\title{
Thyrotropin-Releasing Hormone Increases Behavioral Arousal through Modulation of Hypocretin/Orexin Neurons
}

\author{
Junko Hara, ${ }^{1 *}$ Dmitry Gerashchenko, ${ }^{1 *}$ Jonathan P. Wisor, ${ }^{1}$ Takeshi Sakurai, ${ }^{2}$ Xinmin (Simon) Xie,,${ }^{1,3}$ and \\ Thomas S. Kilduff ${ }^{1}$ \\ ${ }^{1}$ Biosciences Division, SRI International, Menlo Park, California 94025, 2Department of Molecular Neuroscience and Integrative Physiology, Kanazawa \\ University, Kanazawa 920-8640, Japan, and ${ }^{3} \mathrm{AfaSci}$, Inc., Burlingame, California 94010
}

Thyrotropin-releasing hormone (TRH) has previously been shown to promote wakefulness and to induce arousal from hibernation. Expression of TRH-R1 (TRH receptor 1) is enriched in the tuberal and lateral hypothalamic area (LHA), brain regions in which the hypocretin/orexin (Hcrt) cells are located. Because the Hcrt system is implicated in sleep/wake control, we hypothesized that TRH provides modulatory input to the Hcrt cells. In vitro electrophysiological studies showed that bath application of TRH caused concentration-dependent membrane depolarization, decreased input resistance, and increased firing rate of identified Hcrt neurons. In the presence of tetrodotoxin, TRH induced inward currents that were associated with a decrease in frequency, but not amplitude, of miniature postsynaptic currents (PSCs). Ion substitution experiments suggested that the TRH-induced inward current was mediated in part by $\mathrm{Ca}^{2+}$ influx. Although TRH did not significantly alter either the frequency or amplitude of spontaneous excitatory PSCs, TRH ( 100 nM) increased the frequency of spontaneous inhibitory PSCs by twofold without affecting the amplitude of these events, indicating increased presynaptic GABA release onto Hcrt neurons. In contrast, TRH significantly reduced the frequency, but not amplitude, of miniature excitatory PSCs without affecting miniature inhibitory PSC frequency or amplitude, indicating that TRH also reduces the probability of glutamate release onto Hcrt neurons. When injected into the LHA, TRH increased locomotor activity in wild-type mice but not in orexin/ataxin-3 mice in which the Hcrt neurons degenerate postnatally. Together, these results are consistent with the hypothesis that TRH modulates behavioral arousal, in part, through the Hcrt system.

\section{Introduction}

Thyrotropin-releasing hormone (TRH) is a tripeptide hypophysiotropic hormone that is well known to stimulate the release of thyroid-stimulating hormone (Boler et al., 1969; Burgus et al., $1969)$ and prolactin from the anterior pituitary. Through its action on the hypothalamo-pituitary-thyroid (HPT) system, TRH has widespread effects on metabolism and thermogenesis (Hollenberg, 2008). In addition to the hypothalamic nuclei associated with the hypophyseal portal system, TRH mRNA is particularly highly expressed in several other hypothalamic nuclei, the olfactory system, caudate-putamen, thalamic reticular nucleus, granule cell layer of the cerebellum, nuclei raphe magnus and obscurus, and the spinal trigeminal nucleus (Heuer et al., 2000). Two TRH receptors and the TRH-degrading enzyme are also widely expressed in the CNS (Heuer et al., 2000). These data support behavioral and pharmacological studies indicating CNS activities for TRH (Gary et al., 2003; Yamada et al., 2003; Lechan and Fekete, 2006).

\footnotetext{
Received Jan. 27, 2009; accepted Feb. 3, 2009

This work was supported by National Institutes of Health Grants R01AG020584, R01MH061755, and R01MH078194, and the Ministry of Education, Culture, Sports, Science, and Technology of Japan. We thank Maheen Hassan for technical assistance.

*J.H. and D.G. contributed equally to this work.

Correspondence should be addressed to Dr. Thomas S. Kilduff, Biosciences Division, SRI International, Menlo Park, CA 94025. E-mail: thomas.kilduff@sri.com.

DOI:10.1523/JNEUROSCI.0431-09.2009

Copyright $\odot 2009$ Society for Neuroscience $\quad$ 0270-6474/09/293705-10\$15.00/0
}

TRH has excitatory effects throughout the CNS (Lechan and Fekete, 2006). In the thalamus, TRH application to the GABAergic neurons of the perigeniculate (PGN) or thalamocortical cells in the lateral geniculate nucleus results in depolarization and increased membrane resistance (Broberger and McCormick, 2005). TRH application transforms these neurons from the burst-firing mode typically associated with the synchronized cortical activity that occurs during slow-wave sleep to the tonic, single-spike mode of action potential generation associated with desynchronized cortical activity that occurs during wakefulness and rapid eye movement sleep. In the hippocampus, TRH induces membrane depolarization and increases action potential firing of GABAergic interneurons in CA1 stratum radiatum and increases the frequency of $\mathrm{GABA}_{\mathrm{A}}$ receptor-mediated spontaneous IPSCs, suggesting that TRH increases the excitability of interneurons to facilitate GABA release in this brain region (Deng et al., 2006). In vivo, TRH and TRH analogs increase wakefulness, decrease sleep, and reduce cataplexy in narcoleptic canines (Nishino et al., 1997). Intrahippocampal TRH injections provoke arousal from hibernation (Stanton et al., 1982).

The dorsomedial hypothalamic nucleus (DMH) is among the brain regions that express TRH at the highest levels in the CNS (Heuer et al., 2000). DMH lesions markedly reduce circadian rhythms of sleep-wake behavior and locomotor activity (LMA) (Chou et al., 2003). The DMH sends TRH and glutamate projections to the lateral hypothalamic area (LHA). Because the LHA contains the wakefulness-promoting hypocretin/orexin (Hcrt) 
cells (de Lecea et al., 1998; Sakurai et al., 1998), this suggests the possibility that $\mathrm{TRH}$-containing cells in the DMH may be an important relay in the regulation of sleep and wakefulness. Therefore, we hypothesized that the TRH effects on behavioral arousal may be mediated through activation of Hcrt neurons. To test this hypothesis, we characterized the cellular effects of TRH on identified Hcrt neurons and determined whether the effects of direct microinjection of TRH on LMA, a measure of active wakefulness and behavioral arousal, were dependent on an intact Hcrt system. We find that TRH has direct excitatory effects and indirect modulatory effects on Hcrt cells and that the TRHstimulatory effects on LMA, but not body temperature $\left(T_{\mathrm{b}}\right)$, are mediated in part by the Hcrt cells.

\section{Materials and Methods}

Animals. Mice were treated according to guidelines approved by the SRI International Institutional Animal Care and Use Committee in conformance with the United States Public Health Service Guidelines on Care and Use of Animals in Research. Both sexes of orexin/EGFP mice, in which enhanced green fluorescent protein (EGFP) is linked to the hcrt/orexin promoter (Yamanaka et al., 2003b), were used for in vitro studies of Hcrt neurons. For behavioral studies, male orexin/ataxin-3 mice, a transgenic strain in which the Hcrt cells degenerate postnatally and are completely lost by adulthood (Hara et al., 2001), were used. Transgenic mice were backcrossed onto a C57BL/6 background for at least 10 generations and maintained on this isogenic background. Mice were housed with ad libitum access to food and water under a $12 \mathrm{~h}$ light/dark cycle (lights on at 6:00 A.M.) for at least 2 weeks before use in an experiment.

Hypothalamic slice preparation. Hypothalamic slice preparation and the recording conditions used to study orexin/EGFP mice (2-3 weeks of age) followed the procedures described previously (Xie et al., 2006, 2008). Eutopic expression of EGFP fluorescence has been found in $\sim 80 \%$ of Hcrt neurons; immunostaining with an anti-EGFP antibody labels $>95 \%$ of the Hcrt neuron population without any evidence of ectopic expression (Yamanaka et al., 2003b).

Drugs. TRH, tetrodotoxin (TTX), N-(2,6-dimethylphenylcarbamoylmethyl)-triethylammonium bromide (QX-314), 6,7-dinitroquinoxaline2,3-dione (DNQX), DL-2-amino-5-phosphono-pentanoic acid (AP-5), bicuculline (BIC), picrotoxin (PTX), and most laboratory reagents were purchased from Sigma-Aldrich. For the electrophysiological experiments, all drugs were made in stock solution (10-100 mM), dissolved in external solution, and applied either by bath application or, where indicated, by local application close to the recorded neurons.

Electrophysiologic recordings. The procedures used for patch-clamp recording of Hcrt neurons, including isolation of spontaneous EPSCs (sEPSCs), spontaneous IPSCs (sIPSCs), miniature EPSCs (mEPSCs), and miniature IPSCs (mIPSCs), have been described previously (Xie et al., 2006). Current-clamp recordings were performed with a $\mathrm{KCl}$ internal solution. Voltage-clamp recordings were performed using a $\mathrm{KCl}$ internal solution with QX-314 in the pipette. sEPSCs were isolated using $40 \mu \mathrm{M}$ bicuculline, whereas sIPSCs were isolated using $20 \mu \mathrm{M}$ DNQX and $50 \mu \mathrm{M}$ AP-5. Peptide and drug applications were via bath perfusion at a $2 \mathrm{ml} /$ min flow rate. The frequency of sEPSCs or sIPSCs was measured using pClamp (version 9.2; Molecular Devices); only those events with ampli- tudes $>10 \mathrm{pA}$ were used. Frequency and amplitudes were calculated as a mean of the values obtained during an $180 \mathrm{~s}$ recording period.

Animal surgery. Wild-type and orexin/ataxin-3 mice ( $n=6 /$ group) were implanted unilaterally with a guide cannula with the tip positioned in the LHA and an intraperitoneal transmitter (E-Mitters; MiniMitter) to record body temperature $\left(T_{\mathrm{b}}\right)$ and LMA. Mice were anesthetized with isoflurane $\left(5 \%\right.$ for induction and $2-3 \%$ for maintenance, in $100 \% \mathrm{O}_{2}$ ) and placed in a stereotaxic apparatus with an anesthesia mask, and the skull was levelled. For drug infusions, a 23 gauge guide cannula was fixed to the skull using stainless-steel screws and dental cement. Stereotaxic coordinates for the guide cannula placement into the LHA were $1.1 \mathrm{~mm}$ posterior to bregma, $0.8 \mathrm{~mm}$ lateral to the midline, and $3.4 \mathrm{~mm}$ ventral to the skull surface (Paxinos and Franklin, 2001). Guide cannulae were plugged with blunt stylets to avoid occlusion. For drug injections, the injection cannula protruded $1.5 \mathrm{~mm}$ from the tip of guide cannula. After surgery, mice were singly housed in plastic cages that were placed on a telemetry receiver board. LMA and $T_{\mathrm{b}}$ data were captured from the transmitter at $5 \mathrm{~s}$ intervals and averaged in $1 \mathrm{~min}$ bins; mice were allowed to recover for at least $7 \mathrm{~d}$ before experiments.

Drug microinjections. Injections of saline or TRH $(0.1$ and $1 \mu \mathrm{g})$ in a volume of $100 \mathrm{nl}$ were made in a balanced order between 9:00 A.M. and 9:40 A.M., $3 \mathrm{~h}$ after light onset (Zeitgeber time 3) via an injection cannula (outer diameter, $130 \mu \mathrm{m}$; Nanofil 35G Blunt Needle; World Precision Instruments). Injection cannulae were attached to a $0.5 \mu$ l Hamilton microsyringe via PE-20 polyethylene tubing, and the solution was injected over a period of $\sim 15 \mathrm{~s}$. The microinjection procedure involved anesthesia with $5 \%$ isoflurane within 1 or $2 \mathrm{~min}$, removal of the stylet, inserting the injection cannula, injecting the solution, and keeping the injection cannula in situ for an additional $15 \mathrm{~s}$. Confirmation of successful injection was obtained by monitoring the movement of a small air 
A

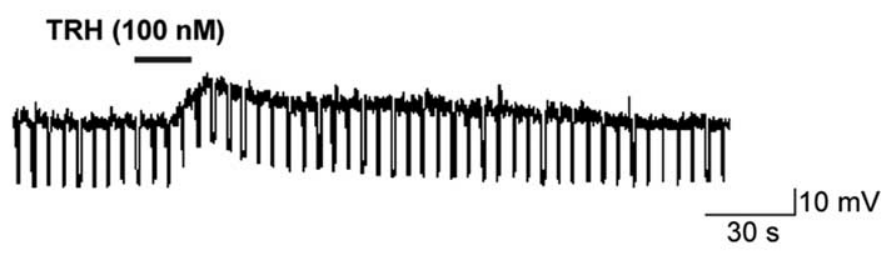

B
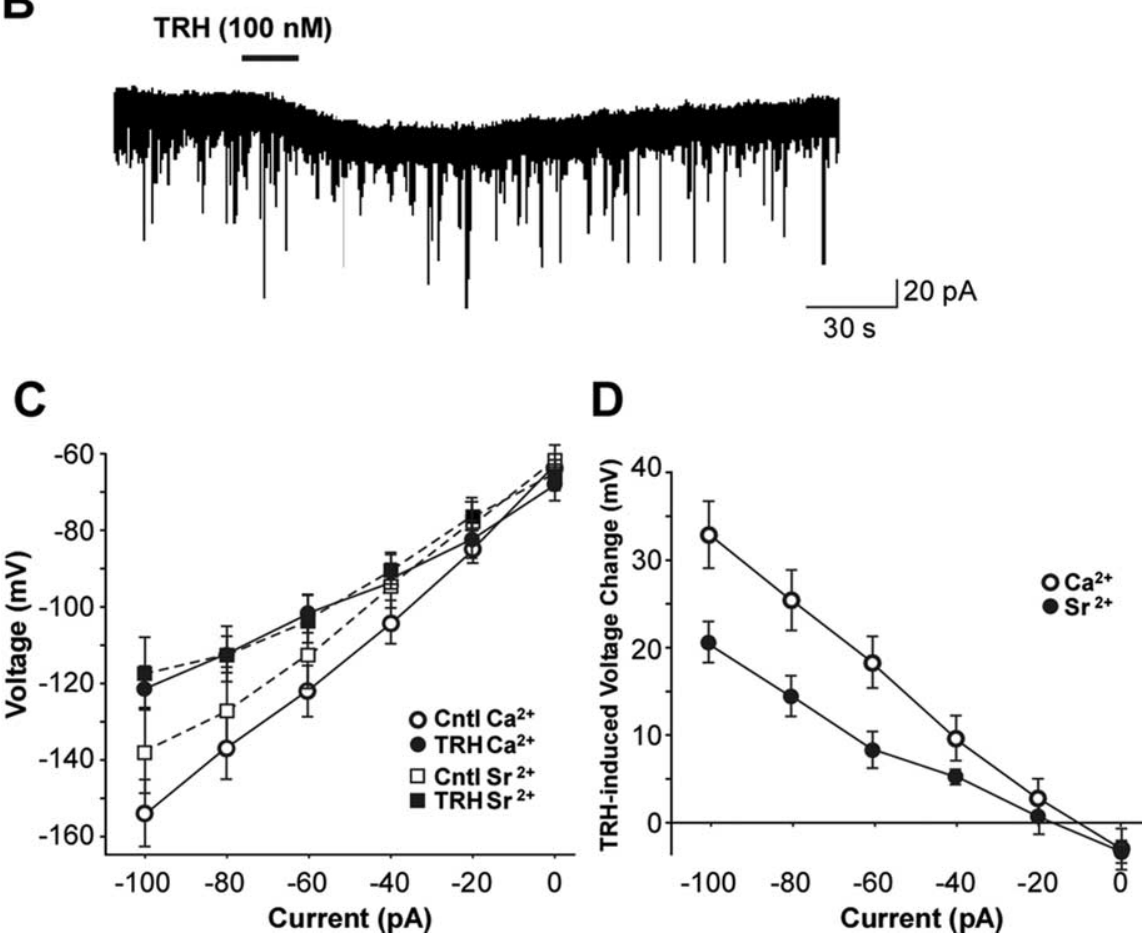

Figure 2. TRH depolarizes hypocretin neurons in the presence of TTX. $\boldsymbol{A}$, Whole-cell current-clamp recording of an Hcrt neuron showing that TRH $(100 \mathrm{~nm})$ depolarized Hcrt neurons in the presence of $0.5 \mu \mathrm{M}$ TTX. B, Representative trace of TRH-induced inward current under voltage-clamp recording at a holding potential of $-60 \mathrm{mV}$. C, I-V relationship under current-clamp recording mode in the presence and absence of TRH when calcium was replaced with strontium in the external medium. $\boldsymbol{D}$, TRH-induced voltage change produced when calcium was replaced with strontium in the external medium. Data were derived from C. Error bars indicate SEM.

bubble in the PE-20 tubing. Mice were ambulatory within 3-5 min after injection. LMA and $T_{\mathrm{b}}$ data were recorded for $2 \mathrm{~h}$ after injection of the TRH or saline. The mice were allowed to recover for $2 \mathrm{~d}$ between TRH or saline injections.

Histological verification of microinjection site. At the end of the experiments, mice were anesthetized with $5 \%$ isoflurane and $100 \mathrm{nl}$ of $10 \%$ FluoroGold solution was microinjected into the brain to mark the microinjection site. Thirty minutes after the FluoroGold injections, mice were perfused with $20 \mathrm{ml}$ of cold PBS followed by $20 \mathrm{ml}$ of $4 \%$ formaldehyde. The brains were removed and cryoprotected in 30\% sucrose. Five sets of coronal sections were cut at $40 \mu \mathrm{m}$ on a freezing microtome and processed for Hcrt immunostaining.

Immunohistochemistry. To detect the Hcrt cells, one set of coronal brain sections from each mouse was incubated overnight at room temperature in the goat anti-orexin B antibody at 1:5000 (sc8071; Santa Cruz Biotechnology). After washing, the sections were incubated with the biotinylated donkey anti-mouse IgG (1:500; Jackson ImmunoResearch) for $2 \mathrm{~h}$ and then reacted with avidin-biotin complex for $1 \mathrm{~h}$ (Vector Laboratories). The DAB (3,3'-diaminobenzidine) method was used to visualize the reaction product. Brain sections were examined under a microscope (Leica DM5000B) equipped with a CCD video camera and photographed.

Statistical analyses. All data are presented as mean \pm SEM. For electro- physiological studies, a two-tailed Student's $t$ test was used to determine significant differences between drug and control conditions. For behavioral studies, group differences were determined using two-way ANOVA, with one factor being genotype and the other being treatment (saline vs low-dose TRH vs high-dose TRH). If the ANOVA was statistically significant, Fisher's PLSD was used to determine group differences. The level of significance was set at $p<0.05$ for all tests.

\section{Results}

Anatomy

The TRH receptor 1 (TRH-R1) is predominantly expressed in the hypothalamus, whereas TRH-R2 is present broadly throughout the brain (Heuer et al., 2000). Using the Allen Brain Atlas (http://mouse. brain-map.org/), we compared the distribution of trh-rl mRNA in the tuberal and lateral hypothalamic region to the distribution of prepro-hort mRNA and found a striking similarity, suggesting that TRH-R1 mRNA might be expressed in Hcrt neurons. Our attempts to demonstrate expression on TRH-R1 on Hcrt cells were thwarted by the absence of a reliable antiserum to recognize TRH-R1, so we relied on electrophysiological criteria, as described below.

\section{In vitro electrophysiology}

Electrophysiological evidence for direct TRH effects on Hcrt neurons

Functional modulation of Hcrt neurons by TRH was evaluated using whole-cell patch-clamp recordings of visually identified Hcrt neurons from orexin/EGFP transgenic mice. Brain slices $(250 \mu \mathrm{m})$ containing the LHA were prepared and orexin/EGFP (i.e., Hcrt) neurons were identified under fluorescence illumination; the same neurons were visualized using infrared-differential interference contrast microscopy to guide electrode placement for patch-clamp recording. The electrophysiological characteristics of the Hcrt neurons recorded were consistent with those we reported previously (Xie et al., 2006, 2008): $V_{\mathrm{m}}=-59.4 \pm 0.9 \mathrm{mV}(n=29)$. Bath application of TRH (100 nM for $20 \mathrm{~s}$ ) caused a depolarization to $-51.1 \pm 1.1$ $\mathrm{mV}$ from a resting level of $-60 \mathrm{mV}(n=13)$, decreased input resistance to $61 \%$ of control $(n=4)$, and increased spontaneous firing of Hcrt neurons (Fig. $1 A$ ). The magnitude of depolarization was concentration dependent (Fig. $1 B$ ). Using a dose-response model (OriginPro 7.5; OriginLab), we estimated the half-maximal effective concentration of TRH-induced depolarization $\left(\mathrm{EC}_{50}\right)$ as $\sim 66 \mathrm{nM}$ with a Hill coefficient of 1.0, suggesting a single binding site. Membrane potential and cell excitability recovered $\sim 2$ min after washout of TRH (Fig. $1 A, C$ ).

To determine whether TRH excited Hcrt neurons directly, TRH was applied in the presence of TTX $(0.5 \mu \mathrm{M})$ under current clamp. As shown in Figure 2 A, TRH (100 nM) consistently depolarized membrane potential $(11.2 \pm 2.2 \mathrm{mV} ; n=7)$ in the presence of TTX. Under voltage-clamp mode at a holding potential 
$\left(V_{\mathrm{h}}\right)$ of $-60 \mathrm{mV}$, TRH induced inward currents $(31.3 \pm 4.5 \mathrm{pA} ; n=3)$ (Fig. $2 B$ ) that were associated with a decrease in frequency of mEPSCs but not mEPSC amplitude. These results suggest a direct postsynaptic action of TRH.

We evaluated the current-voltage relationship of Hcrt neurons in the presence and absence of TRH. The $I-V$ relationship indicated that Hcrt neurons had a membrane resistance of $915 \mathrm{M} \Omega$ in the presence of normal extracellular $\mathrm{Ca}^{2+}(2.4 \mathrm{~mm})$. TRH (100 nM) reduced membrane resistance to $550 \mathrm{M} \Omega(n=4)$ (Fig. $2 C)$. To evaluate the ionic basis for the underlying membrane current, we substituted strontium $\left(\mathrm{Sr}^{2+}\right)(2.4 \mathrm{mM})$ for calcium in the external medium. The membrane resistance changed from $915 \mathrm{M} \Omega$ in the presence of $\mathrm{Ca}^{2+}$ to $760 \mathrm{M} \Omega$ in the presence of $\mathrm{Sr}^{2+}$. TRH reduced membrane resistance to $520 \mathrm{M} \Omega$ in the presence of $\mathrm{Sr}^{2+}(n=4)$ (Fig. 2C). Thus, the TRH-induced change in membrane potential from control was reduced in the presence of $\mathrm{Sr}^{2+}$ compared with $\mathrm{Ca}^{2+}$ conditions (Fig. $2 \mathrm{D}$ ), indicating that the TRH-induced inward current and membrane conductance changes were mediated in part by $\mathrm{Ca}^{2+}$ influx.

TRH modulates Hcrt neuron activity by presynaptic and postsynaptic mechanisms We next tested the effect of TRH on sEPSCs and sIPSCs under voltage-clamp conditions. $\mathrm{GABA}_{\mathrm{A}}$ receptors were blocked with $40 \mu \mathrm{M}$ BIC to pharmacologically isolate sEPSCs. Under voltage clamp with $V_{\mathrm{h}}$ $=-60 \mathrm{mV}$, the mean frequency of sEPSCs was $3.6 \pm 0.8 \mathrm{~Hz}(n=8)$. TRH $(100 \mathrm{nM})$ did not significantly change either the frequency or amplitude of sEPSCs (Fig. $3 A, B)$.

In a separate set of cells, we recorded the frequency and amplitude of sIPSCs in the presence of NMDA and AMPA receptor antagonists AP-5 (50 $\mu \mathrm{M})$ and DNQX $(20 \mu \mathrm{M})$ to block excitatory synaptic transmission (Fig. 3C). Under these conditions, the mean frequency of sIPSCs recorded from Hcrt neurons was $1.3 \pm 0.3 \mathrm{~Hz}(n=$ 14). Bath application of $100 \mathrm{~nm}$ TRH dramatically increased the frequency of sIP-

SCs to $207 \pm 43 \%$ of baseline $(n=14 ; p=0.027)$ but had no effect on the amplitude of these events (Fig. $3 D$ ). In some cells, the frequency of synaptic events recovered after prolonged washout of the peptide. These results indicate that TRH increases the spontaneous release of GABA onto the Hcrt neurons.

To determine whether TRH acts directly at presynaptic terminals to affect the probability of glutamate and GABA release, we examined the effects of TRH receptor activation on the frequency and amplitude of mEPSCs and mIPSCs under voltage clamp at a $V_{\mathrm{h}}$ of $-60 \mathrm{mV}$ (Fig. 4). mEPSCs were pharmacologically isolated by adding BIC $(40 \mu \mathrm{M})$ and TTX $(0.5 \mu \mathrm{M})$ to the external solu- tion. Under these conditions, the mean frequency of mEPSCs was $1.8 \pm 0.3 \mathrm{~Hz}(n=13)$. Bath application of TRH $(100 \mathrm{nM})$ significantly decreased the frequency of mEPSCs to $46.5 \pm 4.0 \%$ of control ( $n=13$; $p<0.0001)$; the amplitude of these events was not significantly altered by TRH (Fig. $4 \mathrm{~B}$ ). mIPSCs were isolated by adding DNQX $(20 \mu \mathrm{M})$, AP-5 $(50 \mu \mathrm{M})$, and TTX $(0.5$ $\mu \mathrm{M})$ to the external solution. Under these conditions, the mean frequency of mIPSCs was $0.6 \pm 0.2 \mathrm{~Hz}(n=4)$. Bath application of TRH (100 nM) had no effect on either mIPSC frequency or amplitude (Fig. $4 D$ ). These results indicate that TRH can reduce the probability of presynaptic glutamate release onto Hcrt neurons. 
A

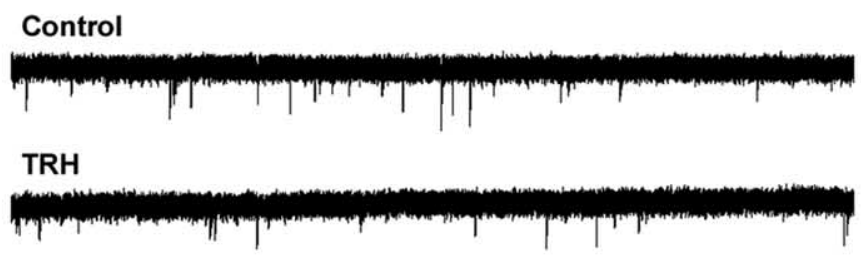

B
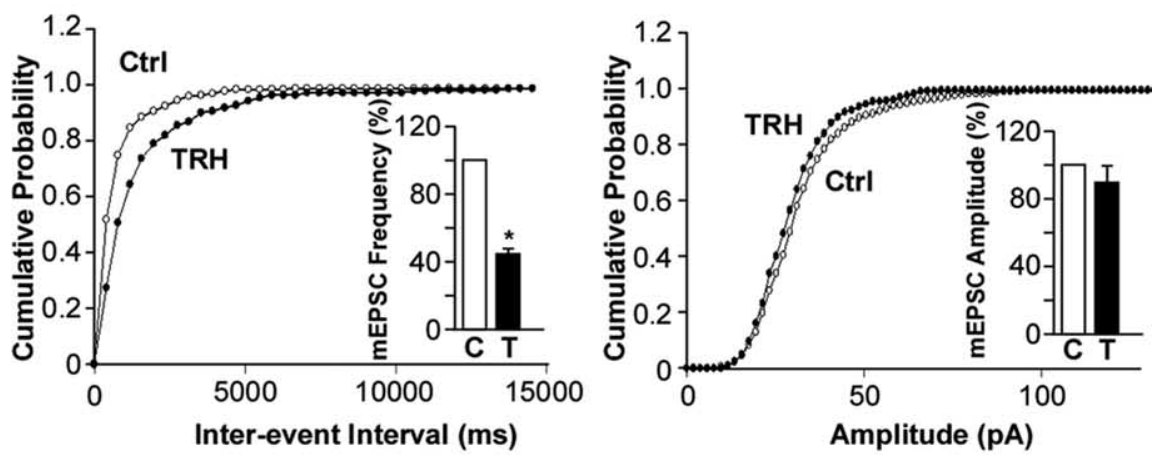

C

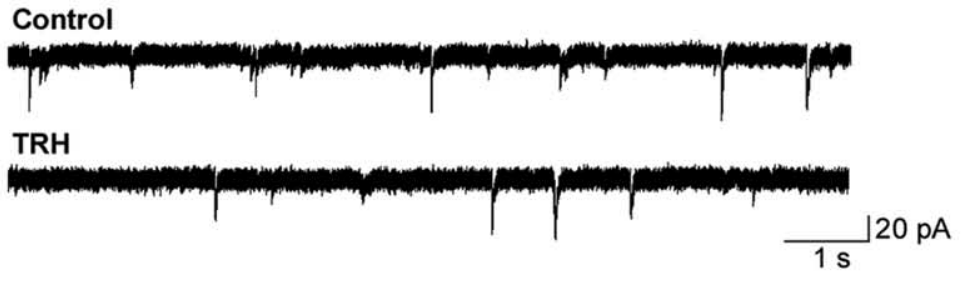

D
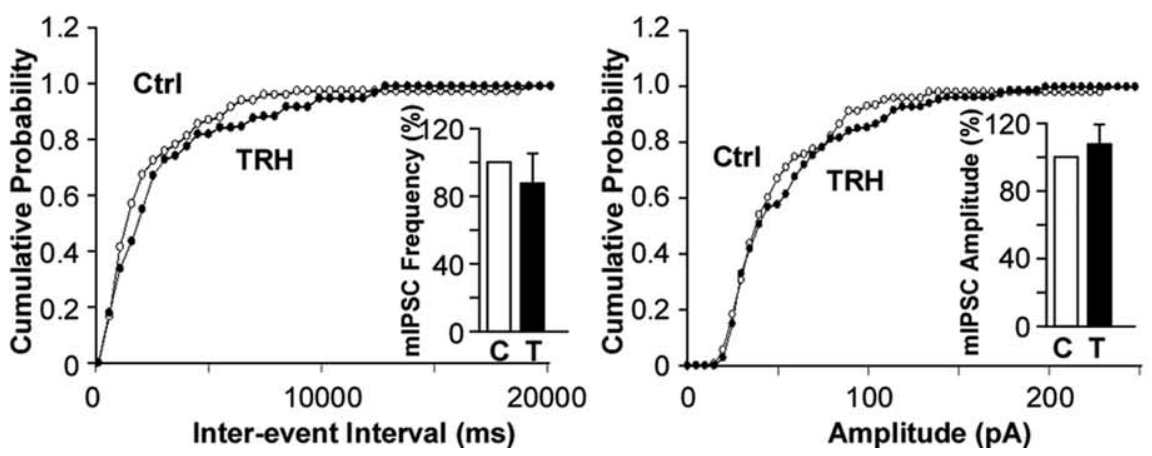

Figure 4. TRH reduces the frequency of miniature EPSCs but not miniature IPSCS recorded in Hcrt neurons. $A$, mEPSCS were recorded by whole-cell voltage clamp at a holding potential of $-60 \mathrm{mV}$ in the presence of TTX ( $0.5 \mu \mathrm{M})$ and bicuculline (40 $\mu \mathrm{m})$. $\boldsymbol{B}$, TRH (100 nm) reduced the frequency $(p<0.0001)$ but not the amplitude of mEPSCs $(n=13) .{ }^{*} p<0.05$. $\boldsymbol{C}$, mIPSCs were recorded by whole-cell voltage clamp at a holding potential of $-60 \mathrm{mV}$ in the presence of TTX (0.5 $\mu \mathrm{M}), A P-5(50 \mu \mathrm{M})$, and DNQX $(20 \mu \mathrm{M})$. D, TRH (100 nM) did not significantly affect either mIPSC frequency or amplitude $(n=4)$. Error bars indicate SEM.

In vivo physiology

Having established that Hcrt neurons are responsive to TRH application in vitro, we sought to identify an in vivo correlate for this activation. To deliver TRH locally into the region of the Hcrt neurons, we implanted cannulae into the LHA of wild-type mice and orexin/ataxin-3 mice in which the Hcrt neurons have been genetically engineered to degenerate postnatally (Hara et al., 2001).

\section{Location of guide cannulae}

The location of injection sites was determined by analysis of FluoroGold fluorescence in brain sections that were stained for $\mathrm{Hcrt}$ (Fig. 5). A group of intensely stained Hcrt-immunoreactive cells
$1 \mathrm{~s}$

$20 \mathrm{pA}$

was seen in the LHA of wild-type mice (Fig. 5A). FluoroGold injections performed subsequent to behavioral pharmacology experiments revealed that the injection sites were located dorsal to the $\mathrm{Hcrt}$ cell field so damage to Hcrt cells by the injection cannula was likely minimal (Fig. $5 B)$. FluoroGold diffused into the brain area occupied by Hcrt cells. Although the diffusion efficiency may differ between the TRH and FluoroGold, the results suggest that TRH diffused in the area of distribution of Hcrt neurons. In orexin/ataxin-3 mice, only a few faintly stained Hcrtimmunoreactive cells were detected in the LHA (Fig. 5C). Therefore, we relied on anatomical landmarks such as the fornix and mammillothalamic tract to determine the location of injection sites in the orexin/ ataxin-3 mice (Fig. 5D).

\section{Effects of TRH on locomotor activity}

To facilitate injections through the guide cannula, mice were briefly anesthetized using isoflurane. The LMA counts were low during first $5 \mathrm{~min}$ after the injection because the mice were under the influence of isoflurane during that period of time. After 5 min postinjection, LMA rapidly increased in all mice (Fig. 6), with the largest increase in LMA observed between 5 and 15 min after the injection of $1 \mu \mathrm{g}$ of TRH in wild-type mice (Fig. 6C). Therefore, we analyzed LMA during this time interval; two-way repeated-measures ANOVA showed significant effects of treatment $(p=0.006)$ and genotype $(p=0.009)$ with no significant genotype by treatment interaction. Fisher's PLSD test revealed that LMA counts were significantly higher in wild-type mice injected with $1 \mu \mathrm{g}$ of TRH $(p<0.05)$ compared with wild-type mice injected with either $0.1 \mu \mathrm{g}$ of TRH or saline; no such effect was seen in the orexin/ataxin-3 mice (Fig. $6 D$ ).

Because recovery from anesthesia has been shown to be dependent on a functional hypocretin/orexin system (Kelz et al., 2008), we evaluated whether the increase in LMA illustrated in Figure 6 might be attributable to a differential effect of anesthesia between the two mouse strains. Male orexin/ataxin-3 $(n=5)$ and litter-matched wild-type control $(n=4)$ mice were implanted with telemeters for measurement of LMA and $T_{\mathrm{b}}$ as described above. After a $7 \mathrm{~d}$ recovery period, mice were anesthetized with $2 \%$ isoflurane for $2 \mathrm{~min}$, and then allowed to recover while LMA and $T_{\mathrm{b}}$ were recorded. Both mouse strains showed a transient increase in LMA that gradually declined over the next 40 min, but there was no difference in LMA between the two strains (Fig. 7A). In contrast, when the same mice were anesthetized with $2 \%$ isoflurane for induction followed by $1.5 \%$ isoflurane for maintenance for $2 \mathrm{~h}$, the increase in LMA in the orexin/ataxin-3 mice was greatly delayed relative to the wild-type mice: whereas 

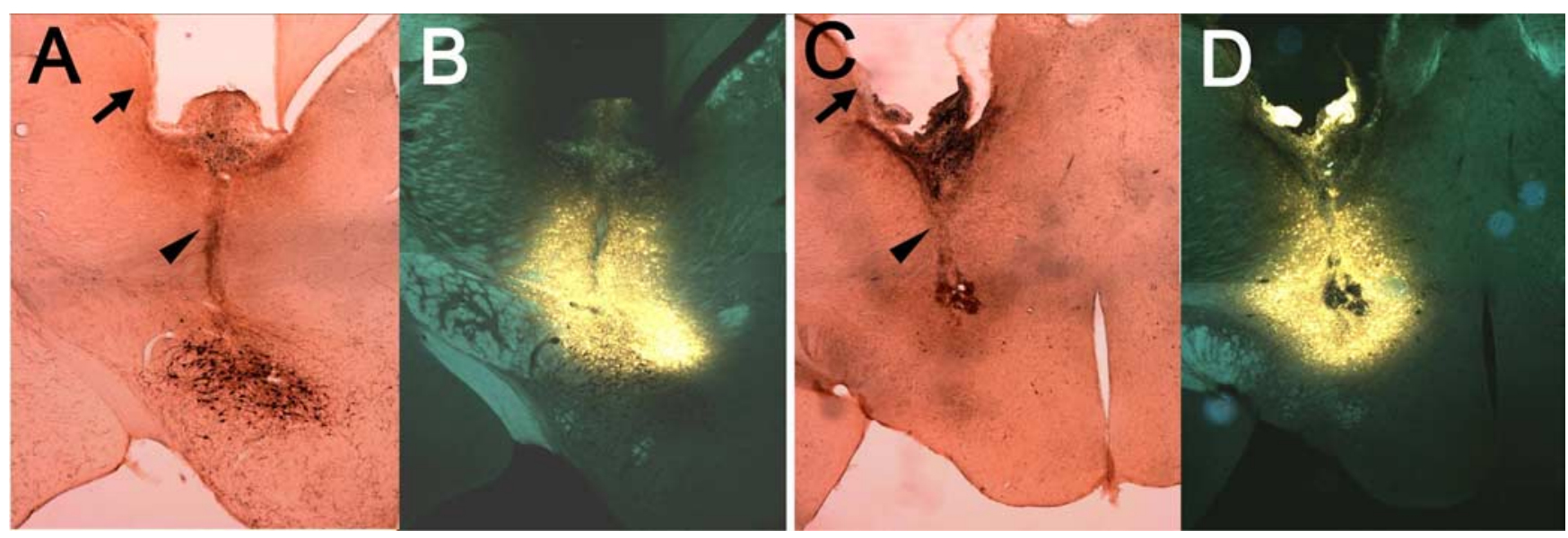

Figure 5. Identification of injection sites in wild-type and orexin/ataxin-3 mice. $A$, Distribution of hypocretin-immunoreactive cells in a representative brain section of a wild-type mouse. The arrows show location of the guide cannula, and the triangles show the tracks of the injection cannula. $\boldsymbol{B}$, Location of the injection site in the same brain section as $\boldsymbol{A}$ is indicated by FluoroGold fluorescence. Note that the location of the injection site is dorsal to the distribution of hypocretin neurons. $C$, In orexin/ataxin-3 mice, there is a dramatic reduction in the number of hypocretinimmunoreactive cells (compare $\boldsymbol{C}, \boldsymbol{A})$. D, The location of FluoroGold injection site in the same brain section from the orexin/ataxin-3 mouse immunostained in $\boldsymbol{C}$.
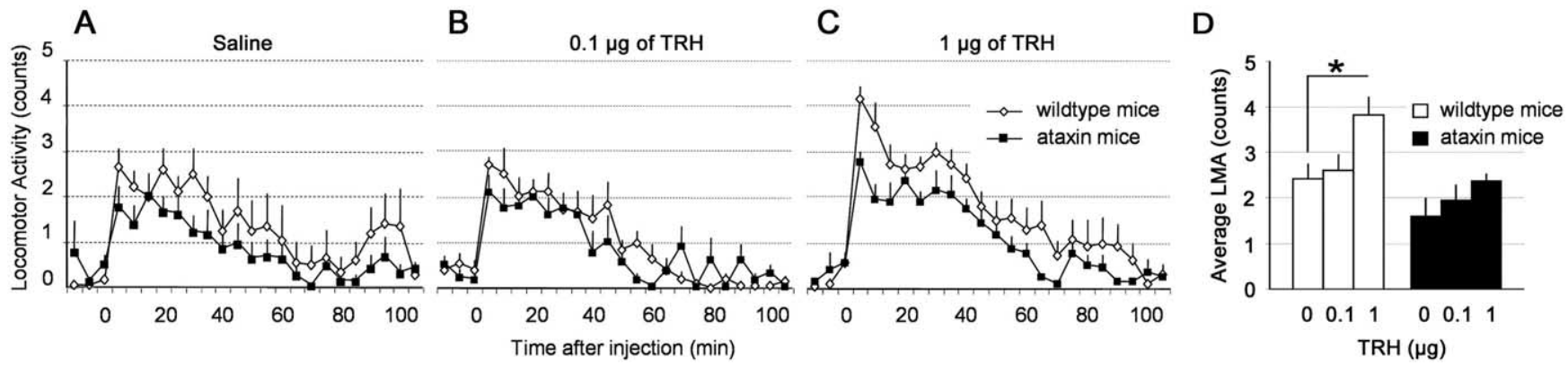

Figure 6. Effect of unilateral TRH injections into the lateral hypothalamus on LMA in wild-type and orexin/ataxin-3 mice. LMA counts recorded by the transmitters were averaged over 5 min intervals. The zero time point represents the LMA calculated during the first 5 min after the injection. $\boldsymbol{A}-\boldsymbol{C}$, Saline $(\boldsymbol{A}), 0.1 \mu \mathrm{g}$ of TRH $(\boldsymbol{B})$, or $1 \mu \mathrm{g}$ of TRH $(\boldsymbol{C})$ was injected in a balanced order through a guide cannula implanted in the lateral hypothalamus in both wild-type $(n=6)$ and orexin/ataxin-3 mice $(n=6)$. $\boldsymbol{D}$, Average LMA counts in the 10 min interval from 5 to 15 min after injection of TRH or saline. TRH at the dose of $1 \mu \mathrm{g}$ produces significantly more LMA counts than saline injection in wild-type mice but not in orexin/ataxin-3 mice. ${ }^{*} p<0.05$ compared with the saline group of the same genotype. Error bars indicate SEM.

an increase in LMA is evident in wild-type mice within $10 \mathrm{~min}$ after cessation of anesthesia, the increase in LMA occurs over a 20-40 min period after cessation of anesthesia in orexin/ataxin-3 mice (Fig. $7 B$ ). Thus, the results from this latter experiment are consistent with the necessity of an intact hypocretin/orexin system for recovery from prolonged anesthesia as described by Kelz et al. (2008). However, the absence of a differential response between the two strains in response to transient anesthesia indicates that the increase in LMA in response to TRH illustrated in Figure 6 is unlikely to be artifactual.

Figure 8 presents the locations of the tip of the injection cannulae for both wild-type mice and orexin/ataxin-3 mice. The average LMA counts during the 5-15 min interval after the injection of $1 \mu \mathrm{g}$ of TRH are color-coded according to the scheme provided in the figure legend. The greatest increase in LMA counts was produced by injection of $1 \mu \mathrm{g}$ of TRH in the wild-type mice in which injection cannulae were located near the core of the Hcrt neurons at $-1.3 \mathrm{~mm}$ from bregma. In two wild-type mice injected at $-2.1 \mathrm{~mm}$ from bregma, there was a small increase in LMA. The change in LMA counts was also small in all orexin/ ataxin-3 mice, although injections were done into the same brain sites in which TRH effectively increased LMA in wild-type mice.

\section{Effects of TRH on body temperature}

The profile of $T_{\mathrm{b}}$ was similar in both strains of mice when injected with TRH or with saline: $T_{\mathrm{b}}$ decreased within first $10 \mathrm{~min}$ after injections and then gradually increased (Fig. 9). When TRH was injected at the dose of $1 \mu \mathrm{g}, T_{\mathrm{b}}$ reached peak levels $\sim 30$ min after the injection and remained at a higher level for at least $60 \mathrm{~min}$. Therefore, we analyzed $T_{\mathrm{b}}$ levels for $60 \mathrm{~min}$ postinjection in both strains. Two-way ANOVA indicated a significant effect of treatment $(p<0.001)$ but no effect of genotype or interaction. Post hoc tests revealed that, in contrast to LMA, $1 \mu \mathrm{g}$ of TRH produced a significant increase in $T_{\mathrm{b}}$ in both mouse strains (Fig. 9D).

\section{Discussion}

Among the hypothalamic nuclei that express TRH, neurons in the medial and periventricular parvocellular divisions of the paraventricular nucleus have received considerable attention because of their projections to the median eminence and their role in release of thyroid-stimulating hormone from the anterior pituitary; these neurons are required for normal function of the thyroid (Hollenberg, 2008). In contrast, TRH-synthesizing neurons in the $\mathrm{DMH}$ have only recently received attention as potential relays between the circadian system and arousal systems located in the LHA (Chou et al., 2003), particularly because LHA neurons express TRH receptors (Heuer et al., 2000). Because Hcrt neurons are the most well understood arousal-related neurons in the LHA, we hypothesized that these cells would be responsive to TRH and that this input might provide important modulatory control of the Hcrt system. Our results demonstrate 

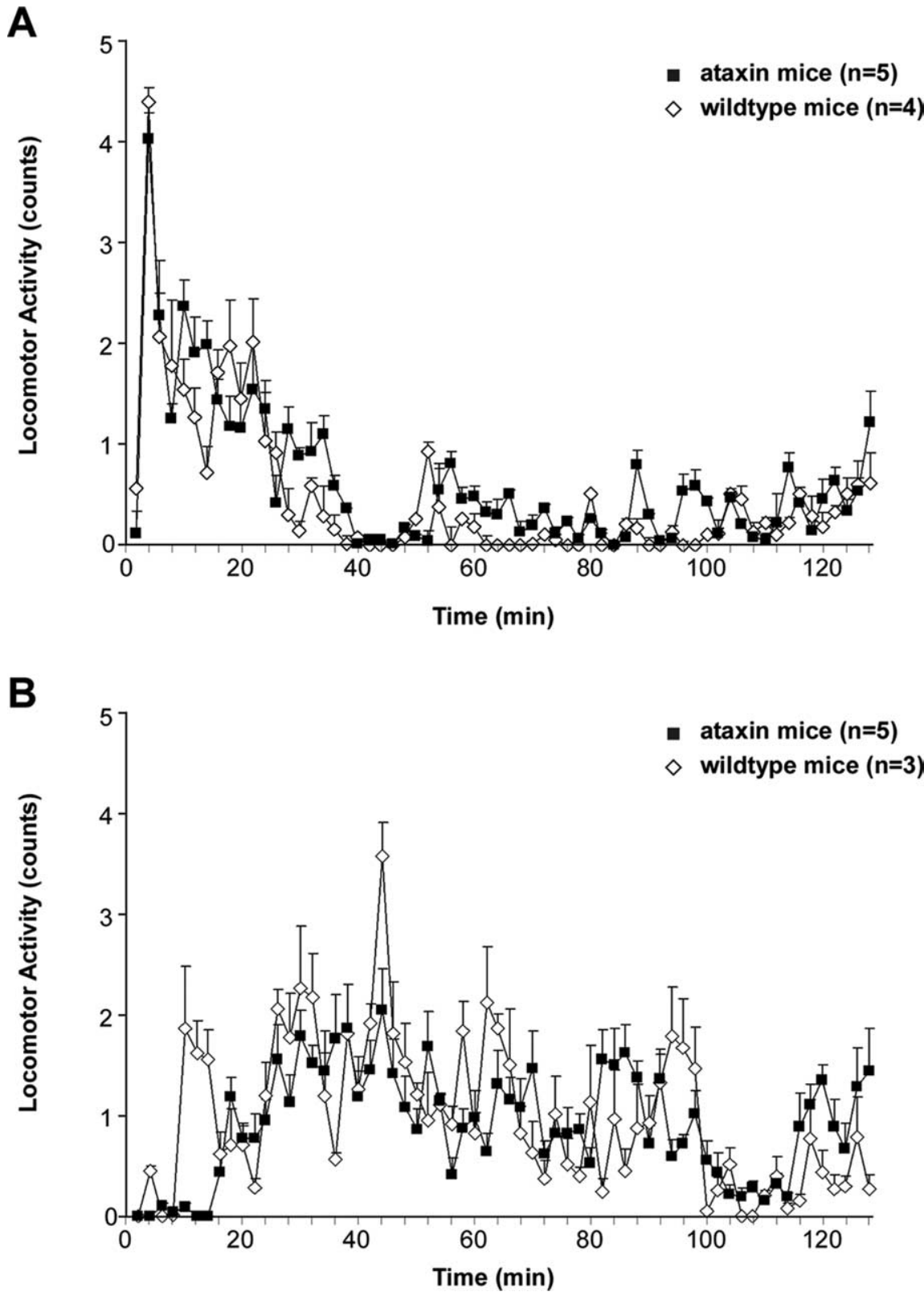

Figure 7. Effects of 2 min versus $2 \mathrm{~h}$ exposure to isoflurane on LMA in orexin/ataxin-3 mice compared with litter-matched controls. $\boldsymbol{A}$, Mice were anesthetized with $2 \%$ isoflurane for $2 \mathrm{~min}$ and then allowed to recover while LMA was recorded. $\boldsymbol{B}$, The same mice were anesthetized with $2 \%$ isoflurane for induction followed by $1.5 \%$ isoflurane for $2 \mathrm{~h}$ and then allowed to recover while LMA was recorded. One week was allowed for the mice to recover between $2 \mathrm{~min}$ and $2 \mathrm{~h}$ isoflurane treatments. Error bars indicate SEM.

that TRH directly excites Hcrt cells in vitro and stimulates LMA in vivo and, therefore, can influence wakefulness and behavioral arousal, in part, through the Hcrt system.

The excitatory effects of TRH on Hcrt neurons, evidenced by concentration-dependent membrane depolarization, decreased input resistance, and increased discharge (Fig. 1), are consistent with previous observations in the thalamus (Broberger and McCormick, 2005) and hippocampus (Deng et al., 2006). Based on recordings of thalamocortical and PGN neurons, increasing levels of TRH appear to shift the activity of thalamic cells from enhancement of spindle activity associated with non-rapid eye movement sleep, to blockade of spindle activity to, at the highest concentrations, induction of the tonic, single-spike activity associated with the desynchronized EEG that occurs during wakeful- ness (Broberger and McCormick, 2005). In the hippocampus, TRH also induces membrane depolarization and increases neuronal discharge of CA1 GABAergic interneurons, suggesting that $\mathrm{TRH}$ increases the excitability of interneurons to facilitate GABA release (Deng et al., 2006). Thus, our results on TRH effects on Hcrt neurons are consistent with the previous literature.

Figure 2 presents evidence that TRH effects on Hcrt neurons are direct and that TRH induces inward currents that are mediated, at least in part, by $\mathrm{Ca}^{2+}$ influx, results consistent with those described in the thalamus (Broberger and McCormick, 2005). The ionic basis for TRH effects has been explored more thoroughly in other systems. TRH induces a slow depolarization that has been attributed to the leak $\mathrm{K}^{+}$ conductance in the spinal cord (Kolaj et al., 1997) and, more specifically, to inhibition of two-pore domain $\mathrm{K}^{+}$channels in hypoglossal motor neurons (Talley et al., 2000), in GABAergic neurons in the thalamus (Broberger and McCormick, 2005), and in CA1 stratum radiatum (Deng et al., 2006). Tandem-pore domain $\mathrm{K}^{+}$channels have previously been described in $\mathrm{Hcrt}$ neurons, and $\mathrm{K}_{2 \mathrm{P}}$ channels are thought to mediate inhibition of Hcrt neurons by glucose (Burdakov et al., 2006). However, $\mathrm{TRH}$ has also been reported to inhibit $\mathrm{Ca}^{2+}$-dependent $\mathrm{K}^{+}$(BK) channels in pituitary cells (Haug et al., 2004), observations consistent with $\mathrm{Ca}^{2+}$-dependent effects of TRH in Hcrt cells (Fig. 2C,D).

In addition to direct effects on Hcrt neurons, TRH exhibited complex indirect effects. The frequency of sEPSCs was approximately threefold greater than sIPSCs; excitatory inputs have previously been described to predominate on Hcrt cells (Horvath and Gao, 2005). TRH had no effect on sEPSCs (Fig. $3 A, B$ ) but reduced mEPSC frequency (Fig. $4 A, B$ ). These results indicate that TRH reduces the probability of glutamate release at presynaptic terminals onto Hcrt neurons. In contrast, TRH increased the frequency of sIPSCs (Fig. 3C,D) without affecting mIPSC frequency (Fig. 4C,D). Similar TRH effects on sIPSCs have been obtained in CA1, CA3, and dentate gyrus neurons (Deng et al., 2006). Furthermore, responses to local GABA application were not enhanced by TRH (data not shown). These observations suggest that TRH activates a GABAergic interneuron to increase GABA release onto Hcrt neurons without altering presynaptic GABAergic terminal release probability.

Having established the cellular effects of TRH on Hcrt neurons, we sought to establish whether these in vitro effects had functional consequences in vivo. TRH has previously been implicated in LMA, including movements such as head swaying, grooming, and chewing (Wei et al., 1975; Ervin et al., 1981; Lin et al., 1987), and TRH injections into the ventromedial hypothala- 

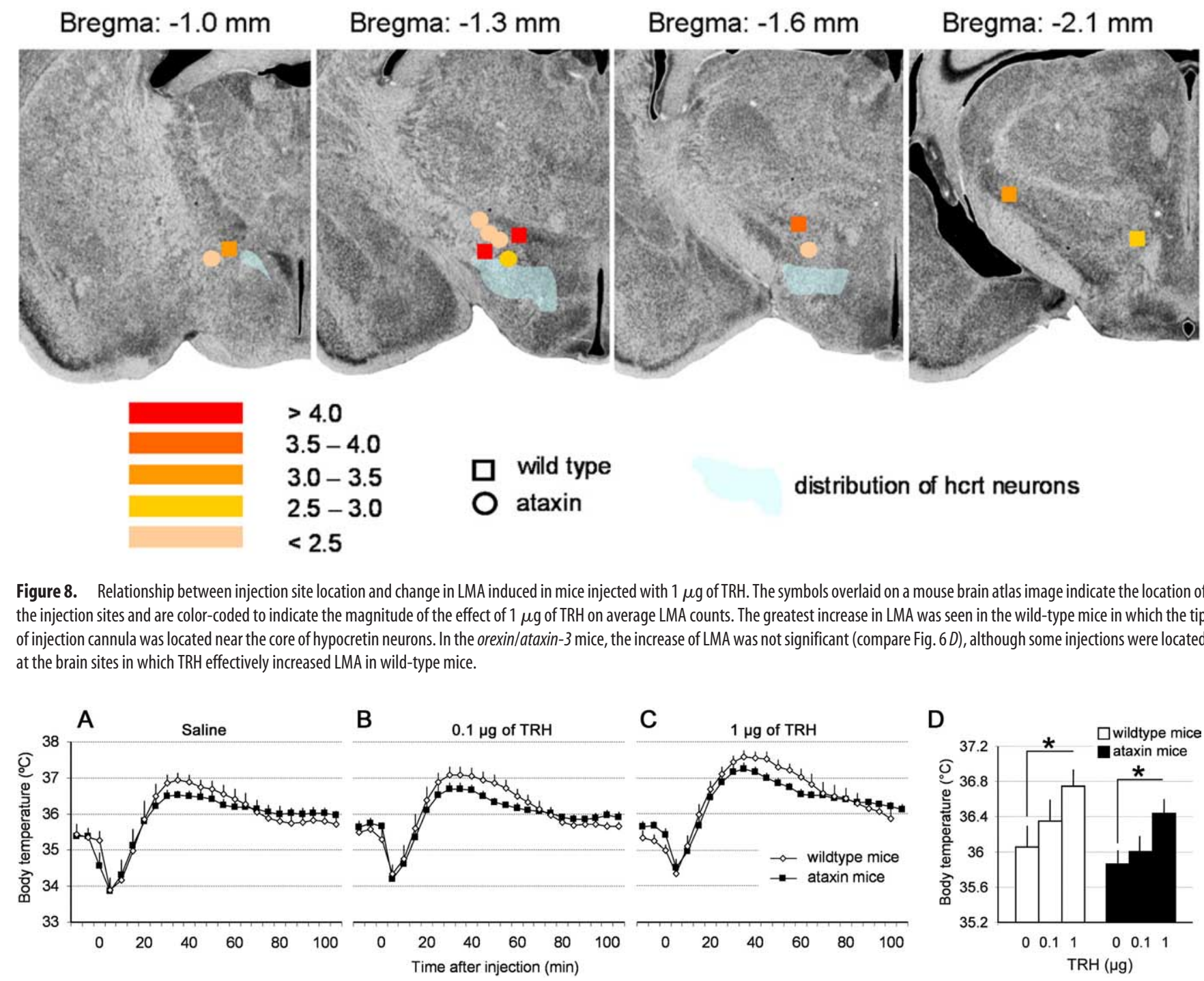

distribution of hert neurons

Figure 8. Relationship between injection site location and change in LMA induced in mice injected with $1 \mu \mathrm{g}$ of TRH. The symbols overlaid on a mouse brain atlas image indicate the location of the injection sites and are color-coded to indicate the magnitude of the effect of $1 \mu \mathrm{g}$ of TRH on average LMA counts. The greatest increase in LMA was seen in the wild-type mice in which the tip of injection cannula was located near the core of hypocretin neurons. In the orexin/ataxin-3 mice, the increase of LMA was not significant (compare Fig. 6D), although some injections were located at the brain sites in which TRH effectively increased LMA in wild-type mice.

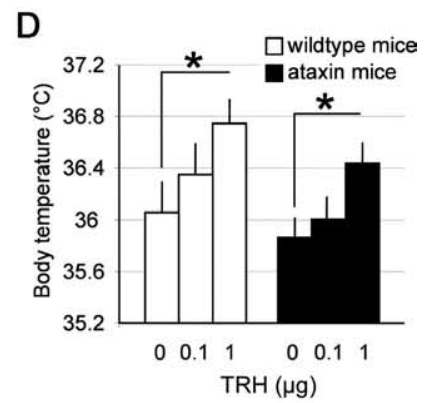

Figure 9. Effect of unilateral TRH injections into the lateral hypothalamus on body temperature. $T_{\mathrm{b}}$ data were averaged over 5 min intervals; the zero time point represents the $T_{\mathrm{b}}$ observed within the first 5 min after the injection. $\boldsymbol{A}-\boldsymbol{C}$, Saline $(\boldsymbol{A}), 0.1 \mu \mathrm{g}$ of TRH $(\boldsymbol{B})$, or $1 \mu \mathrm{g}$ of TRH (C) was injected as described in Figure $6 . \boldsymbol{D}$, Average $T_{\mathrm{b}}$ for the 60 min after injection of TRH or saline in wild-type and orexin/ataxin-3 mice. TRH at the dose of $1 \mu \mathrm{g}$ produces significant increase in $T_{\mathrm{b}}$ compared with saline in both wild-type and orexin/ataxin- 3 mice. ${ }^{*} p<0.05$ compared with the saline group of the same genotype. Error bars indicate SEM.

mus (Lin et al., 1987) and ventral tegmental area (Kalivas et al., 1987) induce locomotion. As indicated in Figures 6-8, TRH injection into the LHA significantly increased LMA in mice; moreover, this effect was dependent on intact Hcrt neurons (Fig. $6 C, D)$. Furthermore, as illustrated in Figure 8, the magnitude of the locomotor response observed was diminished in injection sites that were distant from the core of the Hcrt neuronal population. Together, these results indicate that TRH effects on LMA are dependent, at least in part, on a functional Hcrt system. Although emergence from anesthesia is prolonged in orexin/ ataxin-3 mice (Kelz et al., 2008), the protocol in that study involved a $2 \mathrm{~h}$ exposure to isoflurane rather than the 1-2 min exposure used in the present study to facilitate microinjections.

Although TRH is also well known to play a role in metabolism and thermogenesis through the HPT axis, TRH also has a role in central thermoregulation. When injected intracerebroventricularly, TRH increases $T_{\mathrm{b}}$ and brown fat temperature; these effects can be blocked by pretreatment with TRH-R1 antisera (Shintani et al., 2005). When injected into the anterior hypothalamic-pre- optic area, TRH decreases the activity of warm-sensitive neurons and increases the activity of cold-sensitive neurons (Hori et al., 1988). As indicated in Figure 9, when injected into the region of the Hcrt neurons, TRH significantly increased $T_{\mathrm{b}}$ in both wildtype and orexin/ataxin-3 mice, indicating that, in contrast to the effects on LMA, TRH effects on $T_{\mathrm{b}}$ are not dependent on an intact Hcrt system. These results are remarkable because $T_{\mathrm{b}}$ and LMA are usually correlated.

The results presented here make a compelling case that TRH can activate Hcrt neurons both in vitro and in vivo; Figure 10 summarizes the cellular effects of TRH on Hcrt neurons. Although the experiments in Figure 2 demonstrate direct postsynaptic effects of TRH, they do not preclude the possibility of presynaptic effects. Measurement of sEPSCs and sIPSCs (Fig. 3) combined with measurement of mEPSCs and mIPSCs (Fig. 4) clearly indicate presynaptic effects of TRH. Such presynaptic TRH effects depend on the localization of presynaptic TRH receptors; the increase in sIPSC frequency induced by TRH application (Fig. 3D) is suggestive of TRH receptor localization on 


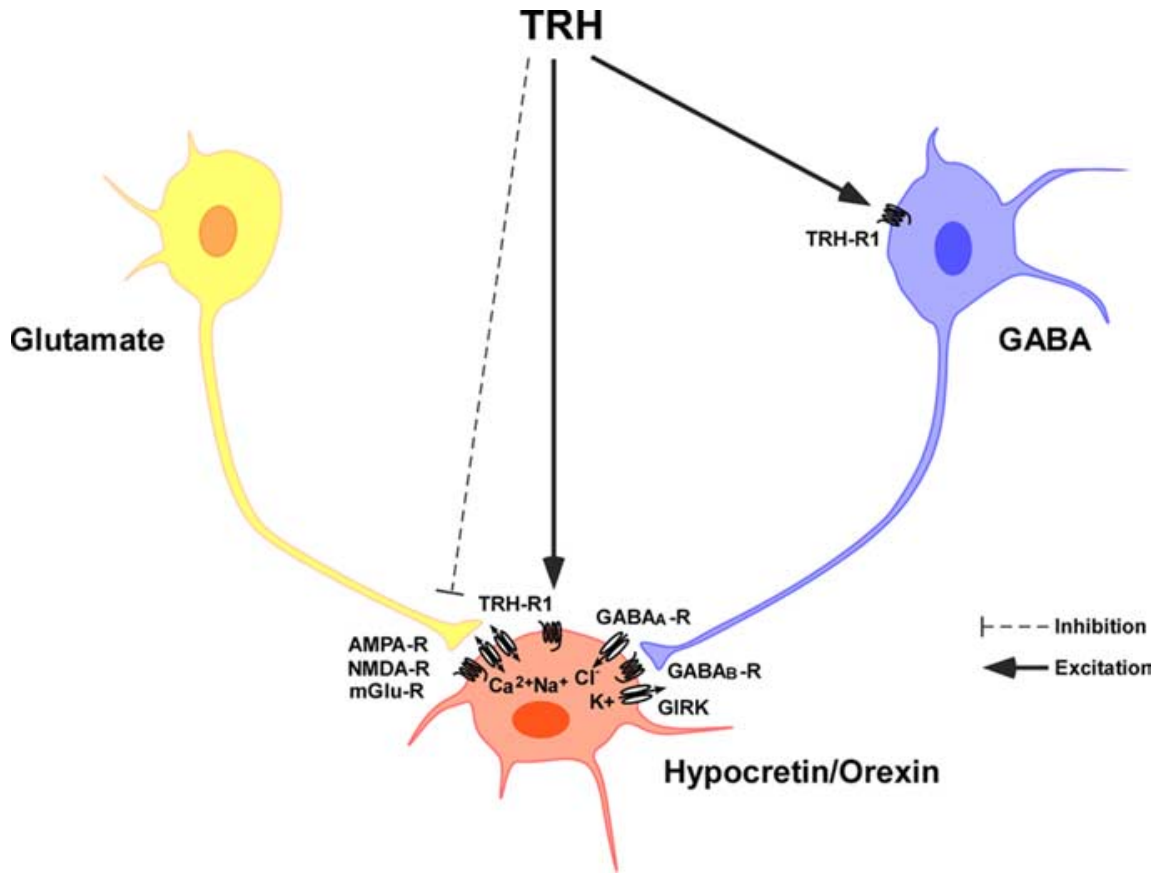

Figure 10. Schematic summarizing the direct and indirect effects of TRH on hypocretin neurons. In addition to direct postsynaptic excitatory effects (presumably mediated by TRH-R1), TRH increases GABA release but reduces the probability of glutamate release at presynaptic terminals.

inhibitory interneurons. Previous studies (Horvath and Gao, 2005) indicate that excitatory inputs to the Hcrt neurons dominate inhibitory inputs by approximately fourfold to fivefold. The fact that TRH increased Hcrt neuron activity (Fig. 1) and produced locomotion, an effect that was dependent on intact Hcrt neurons (Fig. 6), indicates that postsynaptic excitatory TRH effects dominate any presynaptic inhibitory effects. This suggestion is further supported by the absence of a transient GABAmediated presynaptic inhibition before membrane depolarization. Additional exploration of this hypothesis is limited at the moment by the absence of TRH antagonists to evaluate the presence of endogenous TRH tone, for example.

In addition to TRH, cellular electrophysiological studies using orexin/EGFP mice has revealed that Hcrt cells are excited by glutamate ( $\mathrm{Li}$ et al., 2002; Yamanaka et al., 2003a), ghrelin (Yamanaka et al., 2003b), low glucose levels (Yamanaka et al., 2003b; Burdakov et al., 2005, 2006), ATP (Wollmann et al., 2005), corticotrophin-releasing factor (Winsky-Sommerer et al., 2004), glucagon-like peptide 1 (Acuna-Goycolea and van den Pol, 2004), cholecystokinin (Tsujino et al., 2005), neurotensin (Tsujino et al., 2005), and vasopressin and oxytocin (Tsujino et al., 2005; Tsunematsu et al., 2008). Conversely, Hcrt neurons are inhibited by GABA (Li et al., 2002; Yamanaka et al., 2003a; Xie et al., 2006), norepinephrine, dopamine and epinephrine (Li et al., 2002; Yamanaka et al., 2003a, 2006; Li and van den Pol, 2005), serotonin (Li et al., 2002; Yamanaka et al., 2003a; Muraki et al., 2004), neuropeptide Y (Fu et al., 2004), leptin (Yamanaka et al., 2003b), high glucose levels (Yamanaka et al., 2003b; Burdakov et al., 2005; Burdakov et al., 2006), adenosine (Liu and Gao, 2007), cannabinoids (Huang et al., 2007), dynorphin (Li and van den Pol, 2006), Met-enkephalin (Li and van den Pol, 2008), and nociceptin (Xie et al., 2008). However, with few exceptions (Yamanaka et al., 2003b; Muraki et al., 2004; Winsky-Sommerer et al., 2004; Tsunematsu et al., 2008; Xie et al., 2008), information regarding regulation of the Hcrt cells obtained in vitro is rarely evaluated in an in vivo context. The in vivo results presented here demonstrate that TRH can stimulate LMA through the Hcrt system and can thereby affect behavioral arousal; whether TRH effects on sleep and wakefulness (Nishino et al., 1997) are a secondary consequence of the effect on LMA and dependent on an intact Hcrt system remains to be determined. Nonetheless, the results described here are consistent with the concept of a pathway of TRH-synthesizing neurons located in the $\mathrm{DMH}$ that projects to Hcrt cells in the LHA and is involved in behavioral state regulation.

Note added in proof. The effects of TRH on hypocretin neurons have recently been described by Gonzalez et al. (2009).

\section{References}

Acuna-Goycolea C, van den Pol A (2004) Glucagon-like peptide 1 excites hypocretin/ orexin neurons by direct and indirect mechanisms: implications for viscera-mediated arousal. J Neurosci 24:8141-8152.

Boler J, Enzmann F, Folkers K, Bowers CY, Schally AV (1969) The identity of chemical and hormonal properties of the thyrotropin releasing hormone and pyroglutamyl-histidyl-proline amide. Biochem Biophys Res Commun 37:705-710.

Broberger C, McCormick DA (2005) Excitatory effects of thyrotropinreleasing hormone in the thalamus. J Neurosci 25:1664-1673.

Burdakov D, Gerasimenko O, Verkhratsky A (2005) Physiological changes in glucose differentially modulate the excitability of hypothalamic melanin-concentrating hormone and orexin neurons in situ. J Neurosci 25:2429-2433

Burdakov D, Jensen LT, Alexopoulos H, Williams RH, Fearon IM, O’Kelly I, Gerasimenko O, Fugger L, Verkhratsky A (2006) Tandem-pore $\mathrm{K}^{+}$ channels mediate inhibition of orexin neurons by glucose. Neuron 50:711-722.

Burgus R, Dunn TF, Desiderio D, Guillemin R (1969) Molecular structure of the hypothalamic hypophysiotropic TRF factor of ovine origin: mass spectrometry demonstration of the PCA-His-Pro- $\mathrm{NH}_{2}$ sequence (in French). C R Acad Sci Hebd Seances Acad Sci D 269:1870-1873.

Chou TC, Scammell TE, Gooley JJ, Gaus SE, Saper CB, Lu J (2003) Critical role of dorsomedial hypothalamic nucleus in a wide range of behavioral circadian rhythms. J Neurosci 23:10691-10702.

de Lecea L, Kilduff TS, Peyron C, Gao X-B, Foye PE, Danielson PE, Fukuhara C, Battenberg ELF, Gautvik VT, Bartlett II FS, Frankel WN, van den Pol AN, Bloom FE, Gautvik KM, Sutcliffe JG (1998) The hypocretins: hypothalamus-specific peptides with neuroexcitatory activity. Proc Natl Acad Sci U S A 95:322-327.

Deng PY, Porter JE, Shin HS, Lei S (2006) Thyrotropin-releasing hormone increases GABA release in rat hippocampus. J Physiol 577:497-511.

Ervin GN, Schmitz SA, Nemeroff CB, Prange AJ Jr (1981) Thyrotropinreleasing hormone and amphetamine produce different patterns of behavioral excitation in rats. Eur J Pharmacol 72:35-43.

Fu LY, Acuna-Goycolea C, van den Pol AN (2004) Neuropeptide Y inhibits hypocretin/orexin neurons by multiple presynaptic and postsynaptic mechanisms: tonic depression of the hypothalamic arousal system. J Neurosci 24:8741-8751.

Gary KA, Sevarino KA, Yarbrough GG, Prange AJ Jr, Winokur A (2003) The thyrotropin-releasing hormone (TRH) hypothesis of homeostatic regulation: implications for TRH-based therapeutics. J Pharmacol Exp Ther 305:410-416.

Gonzalez A, Horjales-Araujo E, Fugger L, Broberger C, Burdakov D (2009) Stimulation of orexin/hypocretin neurones by thyrotropin-releasing hormone. J Physiol. Advance online publication. Retrieved March 9, 2009. doi:10.1113/jphysiol.2008.167940. 
Hara J, Beuckmann CT, Nambu T, Willie JT, Chemelli RM, Sinton CM, Sugiyama F, Yagami K, Goto K, Yanagisawa M, Sakurai T (2001) Genetic ablation of orexin neurons in mice results in narcolepsy, hypophagia, and obesity. Neuron 30:345-354.

Haug TM, Hafting T, Sand O (2004) Inhibition of BK channels contributes to the second phase of the response to TRH in clonal rat anterior pituitary cells. Acta Physiol Scand 180:347-357.

Heuer H, Schäfer MK, O’Donnell D, Walker P, Bauer K (2000) Expression of thyrotropin-releasing hormone receptor 2 (TRH-R2) in the central nervous system of rats. J Comp Neurol 428:319-336.

Hollenberg AN (2008) The role of the thyrotropin-releasing hormone (TRH) neuron as a metabolic sensor. Thyroid 18:131-139.

Hori T, Yamasaki M, Asami T, Koga H, Kiyohara T (1988) Responses of anterior hypothalamic-preoptic thermosensitive neurons to thyrotropin releasing hormone and cyclo(His-Pro). Neuropharmacology 27:895-901.

Horvath TL, Gao XB (2005) Input organization and plasticity of hypocretin neurons: possible clues to obesity's association with insomnia. Cell Metab $1: 279-286$

Huang H, Acuna-Goycolea C, Li Y, Cheng HM, Obrietan K, van den Pol AN (2007) Cannabinoids excite hypothalamic melanin-concentrating hormone but inhibit hypocretin/orexin neurons: implications for cannabinoid actions on food intake and cognitive arousal. J Neurosci 27:4870-4881.

Kalivas PW, Stanley D, Prange AJ Jr (1987) Interaction between thyrotropin-releasing hormone and the mesolimbic dopamine system. Neuropharmacology 26:33-38.

Kelz MB, Sun Y, Chen J, Cheng Meng Q, Moore JT, Veasey SC, Dixon S, Thornton M, Funato H, Yanagisawa M (2008) An essential role for orexins in emergence from general anesthesia. Proc Natl Acad Sci U S A 105:1309-1314.

Kolaj M, Shefchyk SJ, Renaud LP (1997) Two conductances mediate thyrotropin-releasing-hormone-induced depolarization of neonatal rat spinal preganglionic and lateral horn neurons. J Neurophysiol 78:1726-1729.

Lechan RM, Fekete C (2006) The TRH neuron: a hypothalamic integrator of energy metabolism. Prog Brain Res 153:209-235.

Li Y, van den Pol AN (2005) Direct and indirect inhibition by catecholamines of hypocretin/orexin neurons. J Neurosci 25:173-183.

Li Y, van den Pol AN (2006) Differential target-dependent actions of coexpressed inhibitory dynorphin and excitatory hypocretin/orexin neuropeptides. J Neurosci 26:13037-13047.

Li Y, van den Pol AN (2008) $\mu$-Opioid receptor-mediated depression of the hypothalamic hypocretin/orexin arousal system. J Neurosci 28:2814-2819.

Li Y, Gao XB, Sakurai T, van den Pol AN (2002) Hypocretin/orexin excites hypocretin neurons via a local glutamate neuron-A potential mechanism for orchestrating the hypothalamic arousal system. Neuron 36:1169-1181.

Lin LS, Chiu WT, Shih CJ, Lin MT (1987) Involvement of both opiate and catecholaminergic receptors of ventromedial hypothalamus in the locomotor stimulant action of thyrotropin-releasing hormone. J Neural Transm 68:217-225.

Liu ZW, Gao XB (2007) Adenosine inhibits activity of hypocretin/orexin neurons by the $\mathrm{A} 1$ receptor in the lateral hypothalamus: a possible sleeppromoting effect. J Neurophysiol 97:837-848.

Muraki Y, Yamanaka A, Tsujino N, Kilduff TS, Goto K, Sakurai T (2004) Serotonergic regulation of the orexin/hypocretin neurons through the 5- $\mathrm{HT}_{1 \mathrm{~A}}$ receptor. J Neurosci 24:7159-7166.
Nishino S, Arrigoni J, Shelton J, Kanbayashi T, Dement WC, Mignot E (1997) Effects of thyrotropin-releasing hormone and its analogs on daytime sleepiness and cataplexy in canine narcolepsy. J Neurosci 17:6401-6408.

Paxinos G, Franklin KBJ (2001) Mouse brain in stereotaxic coordinates, Ed 2. San Diego: Academic.

Sakurai T, Amemiya A, Ishii M, Matsuzaki I, Chemelli RM, Tanaka H, Williams SC, Richardson JA, Kozlowski GP, Wilson S, Arch JR, Buckingham RE, Haynes AC, Carr SA, Annan RS, McNulty DE, Liu WS, Terrett JA, Elshourbagy NA, Bergsma DJ, et al. (1998) Orexins and orexin receptors: a family of hypothalamic neuropeptides and G protein-coupled receptors that regulate feeding behavior. Cell 92:573-585.

Shintani M, Tamura Y, Monden M, Shiomi H (2005) Thyrotropinreleasing hormone induced thermogenesis in Syrian hamsters: site of action and receptor subtype. Brain Res 1039:22-29.

Stanton TL, Winokur A, Beckman AL (1982) Seasonal variation in thyrotropin-releasing hormone (TRH) content of different brain regions and the pineal in the mammalian hibernator, Citellus lateralis. Regul Pept 3:135-144.

Talley EM, Lei Q, Sirois JE, Bayliss DA (2000) TASK-1, a two-pore domain $\mathrm{K}^{+}$channel, is modulated by multiple neurotransmitters in motoneurons. Neuron 25:399-410.

Tsujino N, Yamanaka A, Ichiki K, Muraki Y, Kilduff TS, Yagami K, Takahashi S, Goto K, Sakurai T (2005) Cholecystokinin activates orexin/hypocretin neurons through the cholecystokinin A receptor. J Neurosci 25:7459-7469.

Tsunematsu T, Fu LY, Yamanaka A, Ichiki K, Tanoue A, Sakurai T, van den Pol AN (2008) Vasopressin increases locomotion through a Vla receptor in orexin/hypocretin neurons: implications for water homeostasis J Neurosci 28:228-238.

Wei E, Sigel S, Loh H, Way EL (1975) Thyrotrophin-releasing hormone and shaking behaviour in rat. Nature 253:739-740.

Winsky-Sommerer R, Yamanaka A, Diano S, Borok E, Roberts AJ, Sakurai T, Kilduff TS, Horvath TL, de Lecea L (2004) Interaction between the corticotropin-releasing factor system and hypocretins (orexins): a novel circuit mediating the stress response. J Neurosci 24:11439-11448.

Wollmann G, Acuna-Goycolea C, van den Pol AN (2005) Direct excitation of hypocretin/orexin cells by extracellular ATP at P2X receptors. J Neurophysiol 94:2195-2206.

Xie X, Crowder TL, Yamanaka A, Morairty SR, Lewinter RD, Sakurai T, Kilduff TS (2006) $\mathrm{GABA}_{\mathrm{B}}$ receptor-mediated modulation of hypocretin/orexin neurones in mouse hypothalamus. J Physiol 574:399-414.

Xie X, Wisor JP, Hara J, Crowder TL, LeWinter R, Khroyan TV, Yamanaka A, Diano S, Horvath TL, Sakurai T, Toll L, Kilduff TS (2008) Hypocretin/ orexin and nociceptin/orphanin FQ coordinately regulate analgesia in a mouse model of stress-induced analgesia. J Clin Invest 118:2471-2481.

Yamada M, Satoh T, Mori M (2003) Mice lacking the thyrotropin-releasing hormone gene: what do they tell us? Thyroid 13:1111-1121.

Yamanaka A, Muraki Y, Tsujino N, Goto K, Sakurai T (2003a) Regulation of orexin neurons by the monoaminergic and cholinergic systems. Biochem Biophys Res Commun 303:120-129.

Yamanaka A, Beuckmann CT, Willie JT, Hara J, Tsujino N, Mieda M, Tominaga M, Yagami K, Sugiyama F, Goto K, Yanagisawa M, Sakurai T (2003b) Hypothalamic orexin neurons regulate arousal according to energy balance in mice. Neuron 38:701-713.

Yamanaka A, Muraki Y, Ichiki K, Tsujino N, Kilduff TS, Goto K, Sakurai T (2006) Orexin neurons are directly and indirectly regulated by catecholamines in a complex manner. J Neurophysiol 96:284-298. 